\title{
图HAD
}

ISSN-L: 2530-5115

DOI: http://doi.org/10.22585/hospdomic.v2i2.42

\section{La revista Hospital a Domicilio cumplió un año}

\section{The Hospital a Domicilio journal is one year old}

\author{
Equipo editorial de la revista Hospital a Domicilio \\ Alicante, España.
}

\section{Correspondencia/Correspondence \\ editor@revistahad.eu}

Conflicto de Intereses/Competing interest

No existe ningún tipo de conflicto de interés

Financiación/Fundings:

No se declara ninguna fuente específica de

financiación ni ayuda económica recibida.

\section{CÓMO CITAR ESTE TRABAJO | HOW TO CITE THIS PAPER}

Equipo editorial. La revista Hospital a Domicilio cumplió un año. Hosp Domic. 2018;2(2):45-7

Cuando en marzo de 2016 se propuso editar una nueva revista científica sabíamos que nos enfrentábamos a un importante reto, más aun cuando se quería publicar el primer número en enero de 2017. Había que realizar las normas de la revista y configurar los comités editoriales y científicos.

Si bien la publicación en foros especializados no es el único vehículo de difusión de ideas, sí es cierto que es la herramienta más estructurada de comunicación científica. La investigación en las ciencias de la salud se caracteriza por el sometimiento a un método que garantiza, o así debería ser, la objetividad, la fiabilidad, la validez y la reproducción de los resultados. Es decir, las normas editoriales debían estar en línea con las «recomendaciones de uniformidad para la redacción y edición de artículos presentados a revista biomédicas» (1). Que la comunidad científica tuviera claras las reglas del juego.

Al tiempo, había que crear la plataforma de la revista en formato internacional mediante software de código abierto Open Journal Systems (http://revistahad.eu/) y disponer de los primeros artículos. Pero, con el trabajo de unos y la colaboración de muchos estas primeras metas se consiguieron $(2,3)$.

Implementado "el lugar virtual" de la publicación, era fundamental dejar patente la "limpieza" y buen hacer. Toda persona que se acercara a la revista debía tener claro que las reglas estaban bien implantadas y 
la objetividad era patente. Para ello, se postuló toda la plataforma al escrutinio de la Health On the Net Foundation que, en junio de 2017, otorgó la certificación HONcode, acreditando que se cumplía con las normas éticas básicas en la presentación de la información.

Una vez editado el primer número empezó un nuevo reto, conseguir entrar en algunas colecciones de revistas que dieran un primer empujón a la visibilidad. Se sabía que entrar en una suponía un impulso para que la revista fuera aceptada en la siguiente. Por tanto, se trabajó para que fuera admitida en Dialnet, REBIUN (Red Española de Bibliotecas Universitarias) y en la Online Computer Library Center (OCLC-WORLDCAT). Ahora, a lo largo de este segundo año, hay que seguir llamando a la puerta de otras colecciones que amplíen el posicionamiento de nuestra publicación.

Otro tema que preocupó desde el principio, fue conocer la presencia de la revista en la Web. Con ese fin, se la incluyó en el buscador Google Académico que permitía contar con los datos de Google Scholar Metrics (https://goo.gl/4xFW48). A finales de 2017 se comprueba que algunos artículos ya han sido citados, contando Hospital a Domicilio con un índice H igual a 2 (2 artículos han sido citadas dos o más veces).

Por estos logros, el comité editorial esta gratamente sorprendido, pero sabemos que es solo el principio y el camino será muy largo. Tenemos claro que el mundo de la ciencia se ha vuelto muy competitivo. La publicación de artículos científicos en revistas con alto factor de impacto es uno de los parámetros que más se valora en la carrera de los investigadores y aunque este sistema de evaluación de la producción científica no esté, ni mucho menos, exento de críticas, los profesionales relacionados con las ciencias de la salud deben publicar en revistas con alto factor de impacto para intentar, por un lado mejorar la visibilidad de su trabajo y, por otro, engrosar su currículo (4).

Además, para una revista científica los comienzos editoriales son siempre difíciles y se parecen a un bucle de retroalimentación: si una revista no está indizada en las principales bases de datos bibliográficas no le remiten artículos y al no recibir artículos difícilmente conseguirá indizarse (5). Asimismo, si analizamos el proceso evolutivo desde una perspectiva más cercana y su repercusión sobre las revistas españolas, estas publicaciones no se han desempeñado dentro de un panorama que les permitiese incorporarse cómodamente al movimiento de la difusión internacional (6). En consecuencia, hay que tener presente que indizar la revista en las principales bases de datos bibliográficas no será tarea fácil.

Cumplido el primer año, el comité editorial quiere expresar su gratitud a todas las personas que durante este tiempo se han esforzado y han hecho posible que la revista Hospital a Domicilio pueda celebrar su primer aniversario. Será un placer seguir recorriendo el camino junto a ellas y dar la bienvenida a quien quiera colaborar.

\section{BIBLIOGRAFÍA}

1. Wanden-Berghe C. Editorial. Hosp Domic. 2017;1(1):5-6.

2. Massa Domínguez B. La hospitalización a domicilio en el siglo XXI. Hosp Domic. 2017;1(1):7-9.

3. Sanz-Valero J, Wanden-Berghe C, García de Lorenzo A, Gil A, Pérez de la Cruz A, SánchezÁlvarez C, et al; Grupo CDC Nut - SENPE. Las normas de publicación de Nutrición Hospitalaria; un futuro para la revista en beneficio de sus autores. Nutr Hosp. 2007;22(1):1-3.

4. Martínez-Rodríguez R, Baladia E, Romá-Ferri MT, Marques-Lopes I. Publicar en otras revistas citando a la Revista Española de Nutrición Humana y Dietética puede ayudar a conseguir el Impact Factor: Thompson Reuters nos observa. Rev Esp Nutr Hum Diet. 2016;20(1):1-3. DOI: 10.14306/renhyd.20.1.232 
5. Culebras JM. ¡No hay cosa en los cuartetos que me espante! JONNPR J Negat No Posit Results. 2017;2(1):1-2. DOI: 10.19230/jonnpr.1169

6. Veiga de Cabo J. Visibilidad de revistas científicas e iniciativas para incrementar la diffusion de las publicaciones españolas. Nutr Hosp. 2003;53(4)177-80. 